\title{
Visualization of the space of technological parameters of ceramic mixture shaping process as an object of bricks production automation
}

\author{
M.A. Nazarov \\ Samara State Technical University \\ ORCID: 0ooo-0oo1-8365-7208, nazarovm86@yandex.ru
}

\begin{abstract}
An approach is proposed to visualize the working area of the technological parameters of the process of shaping the ceramic mixture, carried out in an auger vacuum extruder, in the production of bricks, which is an important element of the analysis of the stage under consideration as object of automation. The vectors of control and disturbing influences, the vector of controlled coordinates, which make up the shear strain rate and the moisture content of the ceramic mixture in the pressure head, the amount of vacuum in the vacuum chamber of the auger extruder are determined. The well-known experimental data on the influence of the elements of the vector of controlled coordinates on the strength of the finished ceramic brick, and, therefore, in accordance with GOST 5302012 on its mark, have been studied. Evaluation of these dependencies and a number of transformations and manipulations allowed us to represent the sought space of technological parameters of the shaping process in the form of a structural diagram, which is convenient to use when conducting computational experiments, and in the form of a three-dimensional graphic design, the analysis of which allows us to determine the optimum operating modes of an auger vacuum extruder in brick production required brand.
\end{abstract}

Keywords: ceramic brick, auger vacuum extruder, shaping, object of automation, shear rate of ceramic mixture, vacuum in vacuum chamber, moisture of ceramic mixture, brick strength.

\section{Introduction}

Modern requirements for the rational use of raw materials and energy resources for industrial enterprises, including factories producing construction supplies, require innovative development and upgrade of their production facilities. Despite the new types of walling products, the popularity of ceramic bricks remains at a high level, and technological complexes for brick production represent a significant share of the industry. It is important to develop and implement methods and means of controlling the technological process of ceramic bricks manufacture, as it ensures the required quality of the products -with the lowest possible specific energy consumption in each individual case. The creation of algorithms and control systems with similar properties requires a preliminary analysis of the production cycle processes, the selection and justification of technological parameters, that characterize the quality of bricks and determine the causes of defects. The graphical representation of technological variables dependencies simplifies the analysis of the technological process and helps to identify hidden patterns. In this regard, the visualization of the working area of the space of technological parameters for the processes of brick production is considered an important task.

The manufacture of ceramic bricks, carried out most often by plastic shaping, includes several basic steps, at each of which the mechanical, physical, and chemical properties of the raw materials change in a certain way $[1,2]$ : preliminary preparation of raw materials, 
shaping, drying and firing. The peculiarity of this technological chain is in the significant impact of each process on the subsequent stages.

In this paper, we solve the problem of data visualization, that characterize the stage of shaping the ceramic paste in an auger vacuum extruder for the paste wetting, mixing, vacuuming and the extrusion itself. The subsequent analysis of the obtained graphic images will allow to determine the most effective approaches to the management of the considered technological process.

\section{Analysis of the Technological Process of Shaping Ce- ramic Paste in an Auger Vacuum Extruder as an Object of Automation}

The shaping of ceramic paste is one of the most important stages of brick production, determining the quality of the finished product $[3,4]$. The complexity of managing this process is due to its substantial non-linearity, the non-stationary nature of the mechanical, physical and chemical properties of the raw materials, the inability to measure certain technological parameters, and the fact that defects caused by the extrusion step and the deviation of the products from the required value are detected only after drying and firing [4-6]. Nevertheless, rather strict requirements are imposed on ceramic bricks related to their strength, deviations of their geometric shape, absence of defects in the internal structure (concentric and s-shaped cracks, laminated bars, etc.) [7].

The auger vacuum extruder is an aggregated unit that consists of a clay mixer, a vacuum chamber and the extruder [8]. After preliminary preparation, clay feedstock is fed into the loading window of the mixer using a belt feeder for further moistening, steam heating and mixing. Next, the ceramic paste enters the vacuum chamber where the air is extracted from it, adsorbed by the surface of clay particles (causing microcracks in the brick). After vacuuming, the ceramic paste is transported by an auger to the pressure head where the paste is pressed through the head outlet of a given shape resulting in a bar of the desired cross section.

It is known $[4,6,9]$ that the strength value $R$ of finished products under compression depends significantly on the shear rate $\dot{\gamma}$ and the moister level $w$ of the ceramic paste in the pressure head, the value of the vacuum pressure $P_{v}$ in the vacuum chamber of an auger extruder (Fig. 1). Therefore, these parameters make up the vector of controlled coordinates

$$
\mathbf{Y}(t)=\left[\dot{\gamma}(t) P_{v}(t) w(t)\right]^{T},
$$

where $t$ is time; $T$ is the transpose mark.

Shear rate $\dot{\gamma}$ is determined by the auger angular velocity $\omega$ and the flow behavior index of the ceramic paste $\psi[10,11] ; P_{v}$ is determined mainly by the vacuum pump flow rate $Q_{v p}$ and the flow area of the duct, which can vary by $\Delta F$ due to dust and pollution in the vacuum chamber $[6,12] ; w$ depends on the moisture value $w_{o}$ of the raw material entering the clay mixer and the flow rate of the water added to it while mixing $Q_{v}[11,13,14]$. During operation, it is possible to regulate $\omega, Q_{v p}, Q_{v}$ values by varying the frequency of the voltage $\omega_{o a}$, supplying the auger driving motor, the frequency voltage $\omega_{\text {ovp }}$, feeding the driving motor of the vacuum pump, voltage $U_{o s v}$, supplied to the water metering solenoid valve, respectively. In this case, the vector of control actions will be as follows:

$$
\mathbf{U}(t)=\left[\omega_{o q}(t) \omega_{o p}(t) U_{o v}(t)\right]^{T},
$$

The disturbance vector will take the form:

$$
\mathbf{H}(t)=\left[\psi(t) \Delta F(t) w_{\circ}(t)\right]^{T} .
$$




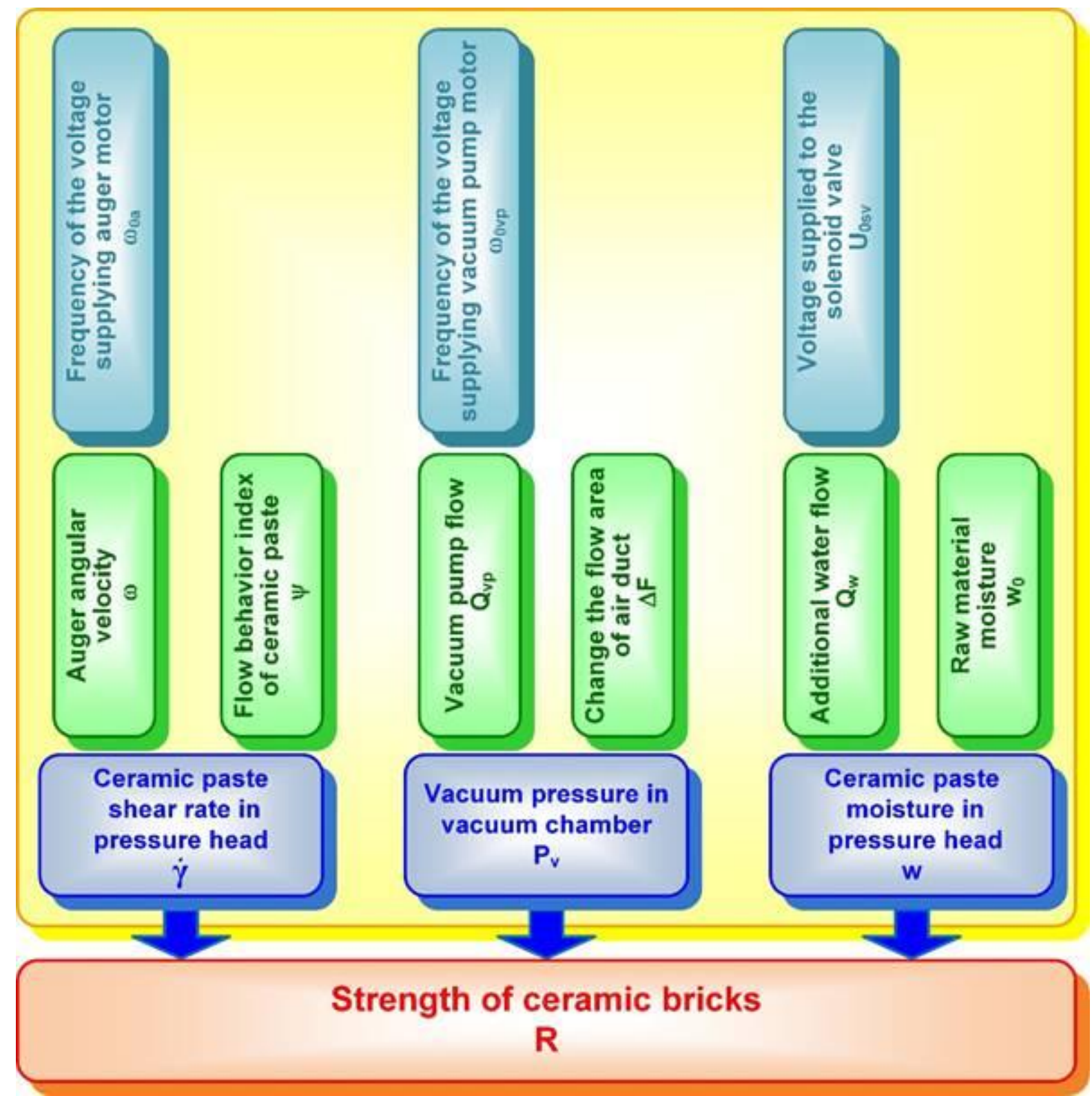

Fig. 1. Influence of the technological parameters of ceramic paste shaping on brick strength $R$.

In order to make the most rational management decisions in the current technological situation, it is necessary to find the optimal position of the operation point in space $\langle\Pi\rangle_{\text {of }}$ the extrusion technological parameters, the coordinates of which are determined by the elements of the vector $\mathbf{Y}$. We suggest that the easiest way for such an approach to be implemented is by visualizing the dependencies between the controlled coordinates of the process and further analysis of the obtained graphical representation.

\section{Influence of the Technological Parameters of Shaping on the Strength of Ceramic Bricks}

Strength class $M$ is one of the brick's main characteristics [7]. Based on the analysis of the requirements described in GOST 530-2012 (Ceramic Brick and Stone. General Technical Conditions) we can suggest that a certain class $M$ is assigned to a brick (provided that the requirements for flexural strength are met) in accordance with the following logical rule: 


$$
M=\left\{\begin{array}{l}
300, \quad R \geq 30 \mathrm{MPa} \\
25 \mathrm{O}, \quad 25 \leq R<30 \mathrm{MPa} ; \\
200, \quad 20 \leq R<25 \mathrm{MPa} \\
175, \quad 17.5 \leq R<20 \mathrm{MPa} ; \\
15 \mathrm{O}, \quad 15 \leq R<17.5 \mathrm{MPa} ; \\
125, \quad 12.5 \leq R<15 \mathrm{MPa} ; \\
100, \quad 10 \leq R<12.5 \mathrm{MPa} \\
75, \quad 7.5 \leq R<10 \mathrm{MPa} ; \\
50, \quad 5 \leq R<7.5 M P a
\end{array}\right\}
$$

In studies [4, 9], the authors present an assessment of the influence of the shear rate $\dot{\gamma}$ in samples made of non-vacuum ceramic paste $\left(P_{v}=O \%\right)$ on their strength $R^{\prime}$ under compression after drying and firing. Every curve $R^{\prime}=\Phi_{1}(\dot{\gamma})$ of the represented family of functional dependencies, corresponding to some fixed moisture value $w$, has approximately the same shape with a pronounced extremum at $\dot{\gamma}=\dot{\gamma}_{R^{\prime} \rightarrow \max }$. We assume that these curves absolutely coincide in shape and are located at the same level relative to the $R^{\prime}$ axis, and as $w$ changes, they shift only along the $\dot{\gamma}$ axis. The analysis of the dependencies presented in studies $[4,9]$ makes it possible to describe the shifting extremum with moisture level variations in the technologically justified range by a quadratic function

where $k_{1}, k_{2}, c_{3}$ are constants.

$$
\dot{\gamma}_{R^{\prime} \rightarrow \text { max }}(w)=k_{1} \cdot w^{2}-k_{2} \cdot w+c_{3},
$$

Based on the data [4, 9] for ceramic samples from Cambrian clay, and taking into account expression (2), we construct a family of curves for five moisture values (Fig. 2). 


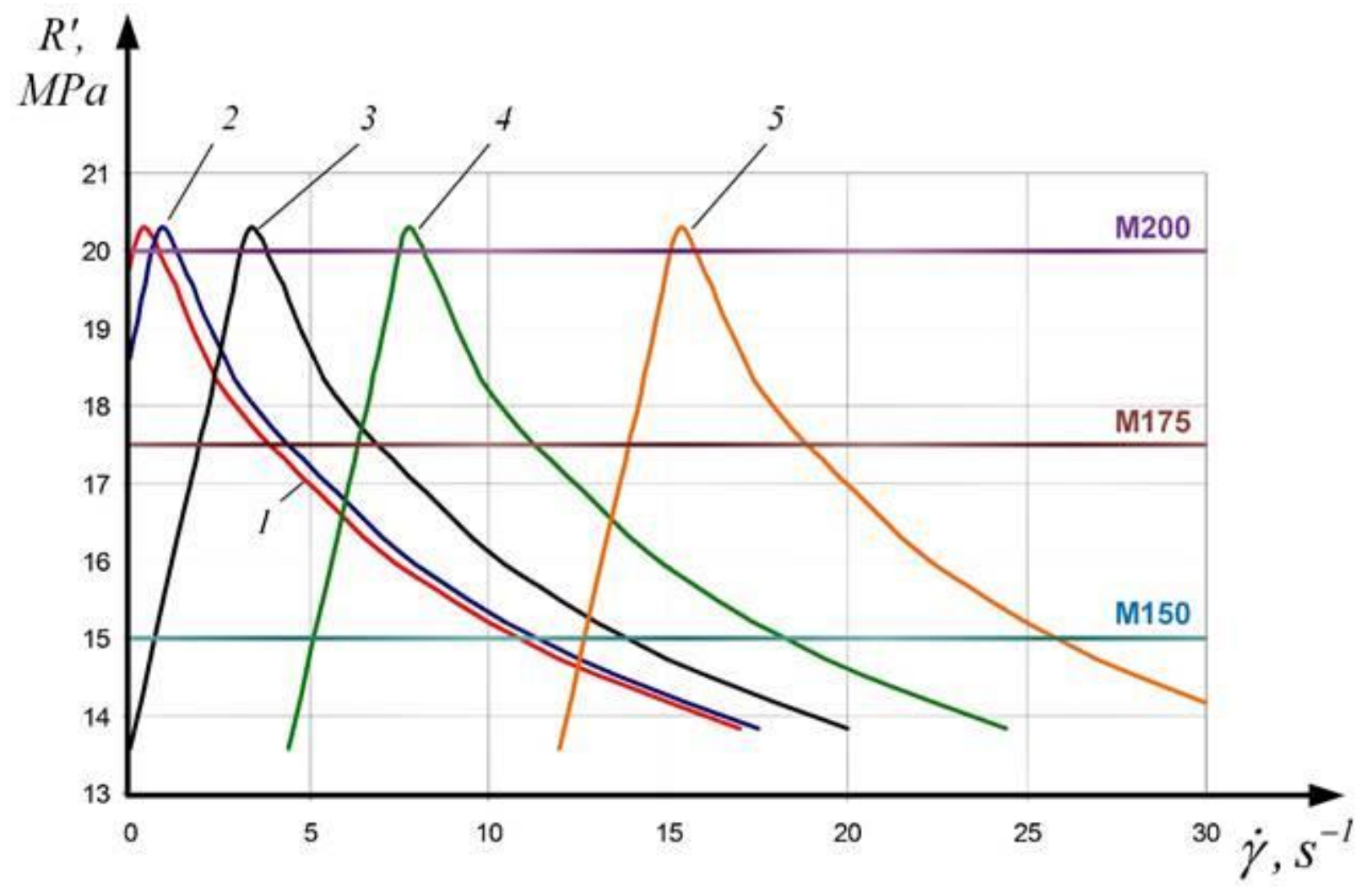

Fig. 2. The dependence of the compressive strength of a brick on the shear rate when shaping a non-vacuum ceramic paste:

$$
\begin{gathered}
1-w=15.5 \% ; 2-w=17.1 \% ; 3-w=19.9 \% ; 4-w=22.5 \% ; \\
5-w=25.5 \% .
\end{gathered}
$$

In the case under consideration, $k_{1}=0.1457 \mathrm{~s}^{-1}, k_{2}=4.4815 \mathrm{~s}^{-1}, c_{3}=34.778 \mathrm{~s}^{-1}$.

Studies of the effect of vaccum processing of the extruded ceramic paste [6] revealed that no increase in strength $R$ was observed at vacuum level of $40 \div 60 \%$, at $80 \div 90 \%$ the strength increased by $70 \%$. Based on these conclusions, we introduce the concept of hardening coefficient $K_{h}$ [12], which is described as the ratio of the strength $R$ of a finished brick obtained from a vacuum processed paste (where $R$ depends on the vacuum level) to the strength $R^{\prime}$ of a brick made of non-vacuum paste

$$
K_{h}\left(P_{v}\right)=R\left(P_{v}\right) / R^{\prime} \text {. }
$$

Let us construct the dependence of the hardening coefficient $K_{h}$ on the vacuum level $P_{v}$ (Fig. 3), and select the area of acceptable variation in the vacuum level (on the condition of excluding defective products by appearance), which is in the range $\min P_{v}^{a c c} \leq P_{v}^{a c c} \leq \max P_{v}^{a c c}$. Based on [6] $-\min P_{v}^{a c c}=70 \%, \max P_{v}^{a c c}=100 \%$, optimal value $P_{v}^{\text {opt }}=90 \%$. 


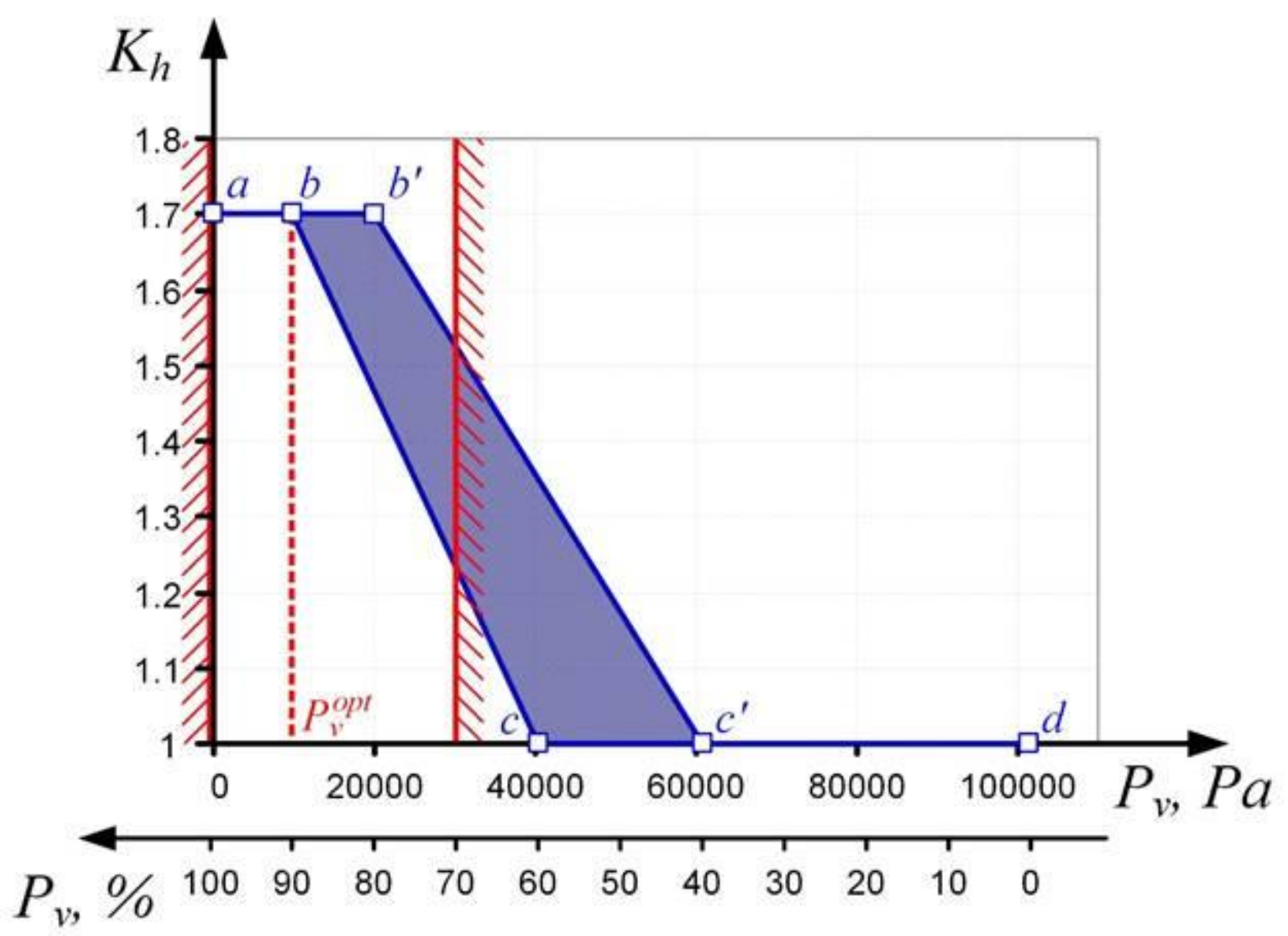

Fig. 3. Dependence of the hardening coefficient of ceramic bricks on the vacuum pressure in vacuum chamber of an auger extruder.

It can be noted that the change in the hardening coefficient $K_{h}$ can occur between the $a b c c^{\prime} d$ and $a b b^{\prime} c^{\prime} d$ polylines, and according to the data in [6] it is not possible to identify the pattern that more accurately determines the increase in strength of ceramic bricks during vacuuming of raw materials used for their production. Therefore, for further analysis here, we will use the option that requires a higher vacuum level, that is, the abcc'd polyline, which will increase the likelihood of obtaining the expected hardening effect. The polyline abcc'd is a graph of a non-linear function $K_{h}=\Phi_{2}\left(P_{v}\right)$.

The presented dependences illustrate the influence of the vector elements of controlled coordinates $\mathbf{Y}$ separately, but do not provide a holistic picture and do not allow to determine the optimal $\dot{\gamma}, w, P_{v}$ values, ensuring the operation of the unit in the most rational mode for the current technological situation. In this regard, it is advisable to create a generalized space of technological parameters of the ceramic paste extrusion process $\langle\Pi\rangle=\Phi_{3}\left(\dot{\gamma}, P_{v}, w\right)$

3. Graphic Synthesis of the Space of Technological Parameters of the Ceramic Paste Extrusion Process

A structural diagram is one of the options for representing the space of technological parameters of the ceramic paste extrusion process $\langle\Pi\rangle$. This method makes sense if the space $\langle\Pi\rangle$ need to be embedded in the computational model of the brick production process. In this case, to reduce the number of manipulations with data arrays, we advise to use only one family curve in the structural diagram $R^{\prime}=\Phi_{1}(\dot{\gamma})$ at some selected base value of 
moisture $w b$, and cast the current value of the shear rate $\dot{\gamma}$ to an equivalent value $\dot{\gamma}^{\prime}$ according to the expression

$$
\dot{\gamma}^{\prime}(w)=\dot{\gamma}-\dot{\gamma}_{c}(w)
$$

where $\dot{\gamma}_{c}$ is the value of the shear rate correction,

$$
\dot{\gamma}_{c}(w)=\dot{\gamma}_{R^{\prime} \rightarrow \max }(w)+\left.\dot{\gamma}_{R^{\prime} \rightarrow \max }\right|_{u=u_{b}}=k_{1} \cdot w^{2}-k_{2} \cdot w+c_{3}+\left.\dot{\gamma}_{R^{\prime} \rightarrow \max }\right|_{u=u_{3}} ;
$$

$\left.\dot{\gamma}_{R^{\prime} \rightarrow \max }\right|_{u=u,}$ is the curve $R^{\prime}=\Phi_{1}(\dot{\gamma})$ extremum, corresponding to the moisture value $w_{b}$. Thus, the extrusion process can be modelled at any moisture value of the ceramic paste using only one curve of the dependence of the brick strength on the speed of shear deformations.

The combination of expressions (1) - (3) and non-linear functional dependencies of $\Phi_{1}$ and $\Phi_{2}$ allows to create a structural representation of the space of technological parameters of the ceramic paste shaping process (Fig. 4). However, this form of display, convenient for use in computational experiments, does not allow for a thorough analysis of this threedimensional dependence, or to reveal its hidden properties. Therefore, it is obviously necessary to introduce the space $\langle\Pi\rangle$ in the form of three-dimensional graphic design in the coordinates of technological variables $-\dot{\gamma}, w, P_{v}$. The solution of this problem is accomplished by graphic synthesis with several stages.

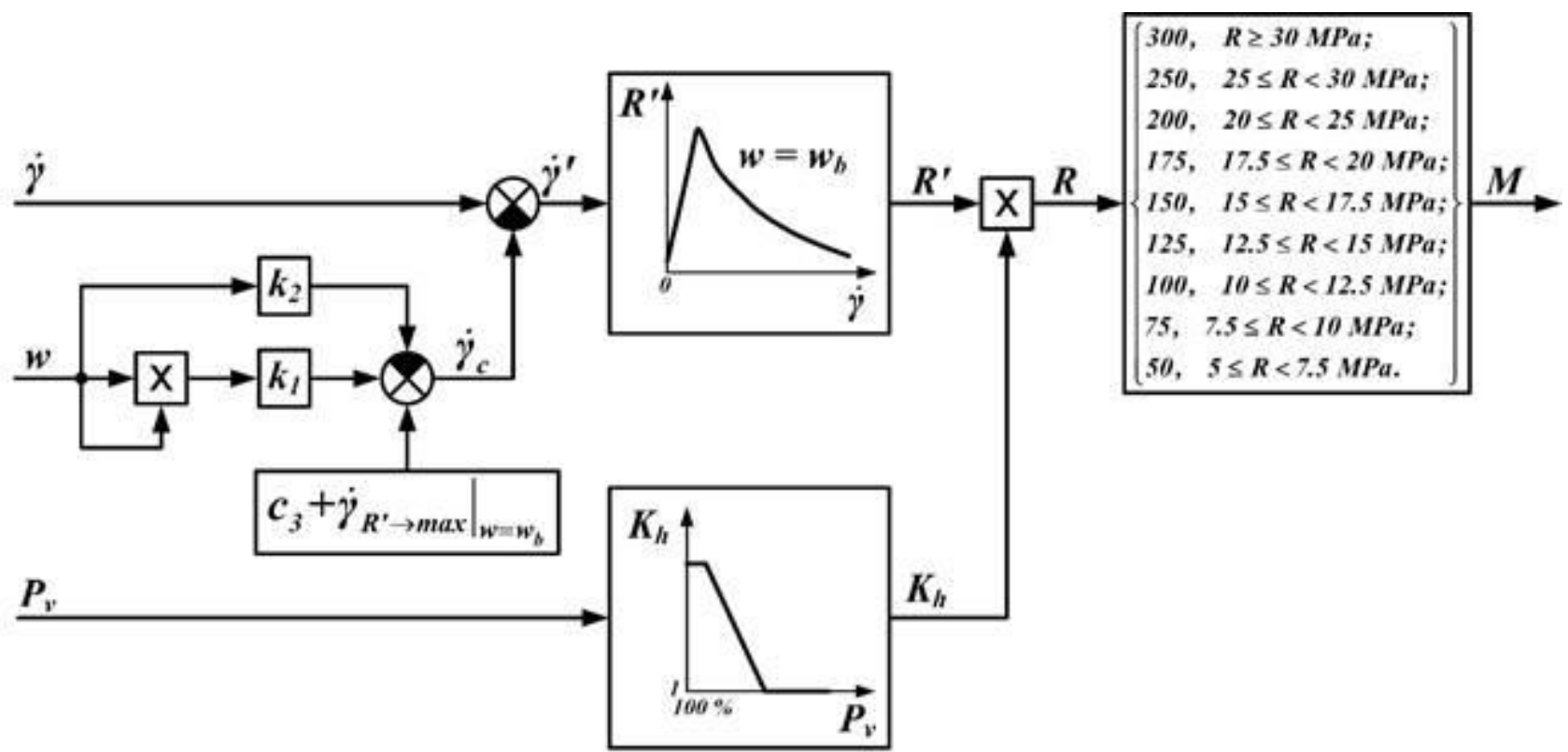

Fig. 4. Structural representation of the space of technological parameters of the ceramic paste extrusion process.

Projecting function graphs $R^{\prime}=\Phi_{1}(\dot{\gamma})$ (Fig. 2), where the boundaries of brick strength classes $M$ are also indicated in accordance with expression (1), on $\dot{\gamma}-w$ plane allows to get a group of curves $\dot{\gamma}=\Phi_{4}(w)$, each of which corresponds to a specific value of $R^{\prime}$. Further, we use only some of these curves, which will be boundary in terms of the separation of $\dot{\gamma}-w$ plane into class areas. We should also take into account that for Cambrian clay the optimum shaping moisture value $w_{s}$ is about $23.5 \%$ [5], and we will take $\Delta w_{a c c}= \pm 1 \%$ [15] as the acceptable range. Minding these limitations, we obtain a set of work areas of an 
auger extruder (in terms of $\dot{\gamma}$ and $w$ ) (Fig. 5), within which it is possible to ensure the production of a brick of a certain class from a non-vacuum ceramic paste. In fact, the formed image is a cross-section of space $\langle\Pi\rangle_{\text {with } P v}=0 \%-\left.\langle\Pi\rangle\right|_{P_{v}=0 \%}$.

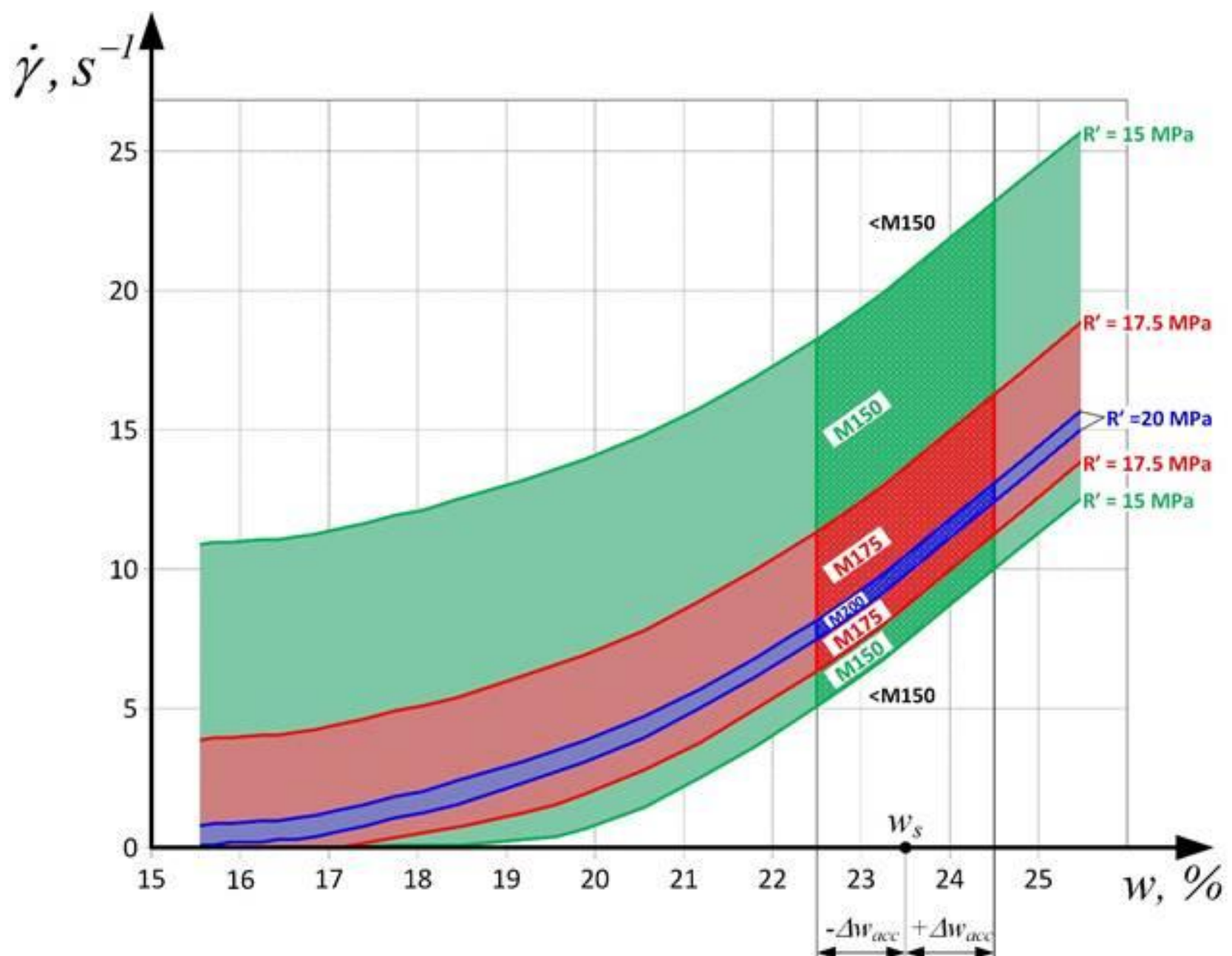

Fig. 5. The cross-section of the space of technological parameters of the ceramic paste extrusion process in $\dot{\gamma}-w$ plane.

We should find the sought space $\langle\Pi\rangle$ by multiplying the elements of the set $\left.\langle\Pi\rangle\right|_{P_{v}=0 \%}$ by the hardening coefficient, which lies in $\min K_{h} \leq K_{h} \leq \max K_{h}$ range. According to the above data, $\min K_{h}=1, \max K_{h}=1.7$. Thus, given the expression (3), we synthesize a three-dimensional space: $\langle\Pi\rangle=\left.K_{h}\left(P_{v}\right) \cdot\langle\Pi\rangle\right|_{P_{v}=0 \%}$.

Let us present $\langle\Pi\rangle$ in the form of a set of surfaces $\left.\langle\Pi\rangle\right|_{P_{v}=P_{v, i}}(i \in 1,2, \ldots, n)$ (Fig. 6), limiting ourselves to the consideration of four values of $P_{v . i}$ from the allowable range of changes in the vacuum pressure of the vacuum chamber of an auger extruder in the process of shaping ceramic paste for brick production: $P_{v \cdot 1}=\min P_{v}^{a c}=70 \%, P_{v .2}=80 \%$, $P_{v \cdot 3}=P_{v}^{o p t}=90 \%, P_{v .4}=\max P_{v}^{a c c}==100 \%$. This series of values determine the values 
of the hardening coefficient $K_{h . i}-K_{h .1}=1.23, K_{h .2}=1.47, K_{h .3}=K_{h .4}=\max K_{h}=1.7$. Using this kind of visualization clearly shows the areas of constant values of brick strength classes in space $\langle\Pi\rangle=\Phi_{3}\left(\dot{\gamma}, P_{v}, w\right)$ (Fig. 6).

Sections $\langle\Pi\rangle_{\text {in }} P_{e}-\dot{\gamma}$ plane (Fig. 7) record working range of the unit, which provide for the production of bricks of a certain class with fixed values of $w$.

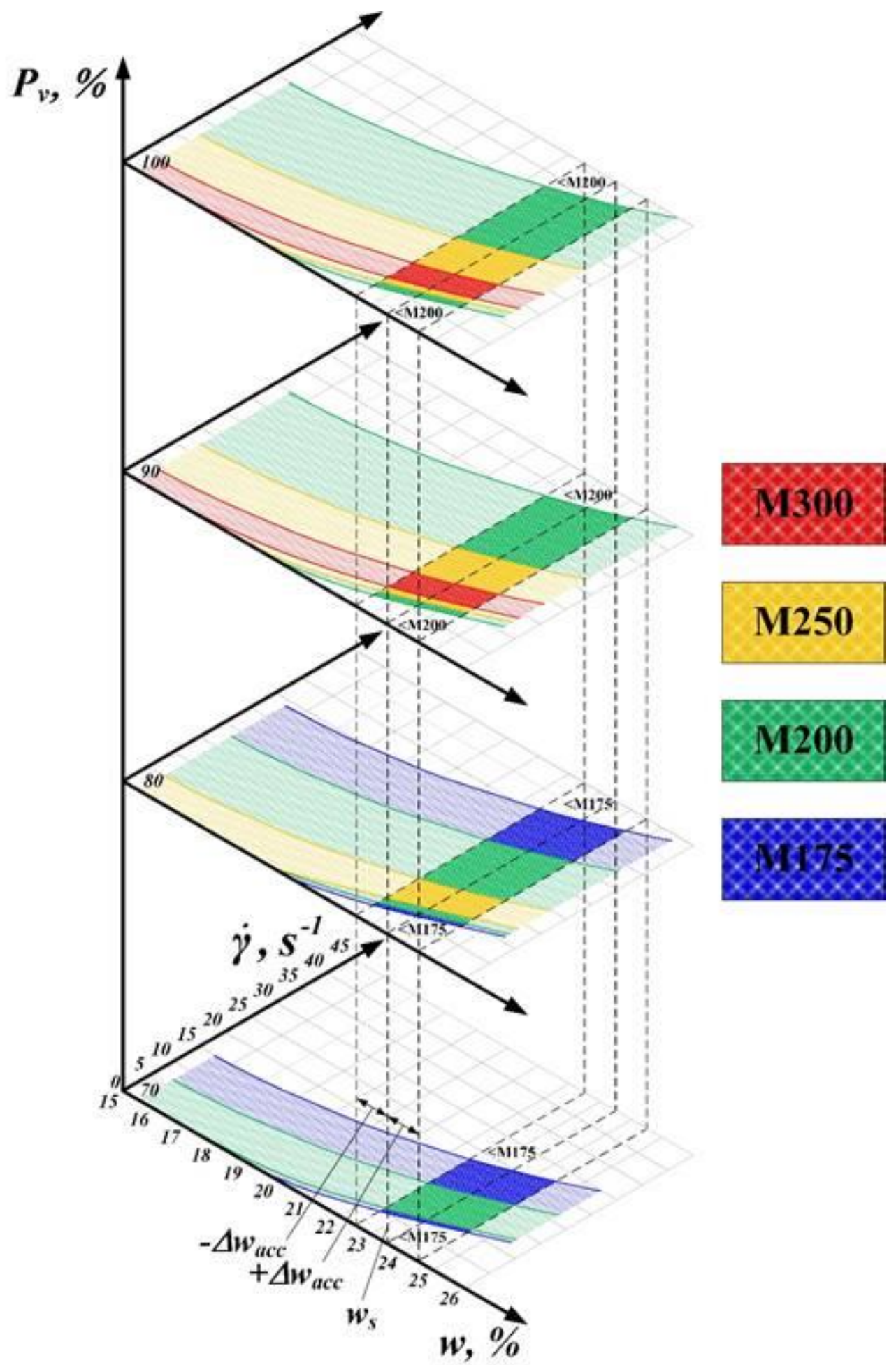

Fig. 6. Three-dimensional visualization of the space of technological parameters of the ceramic paste extrusion process. 

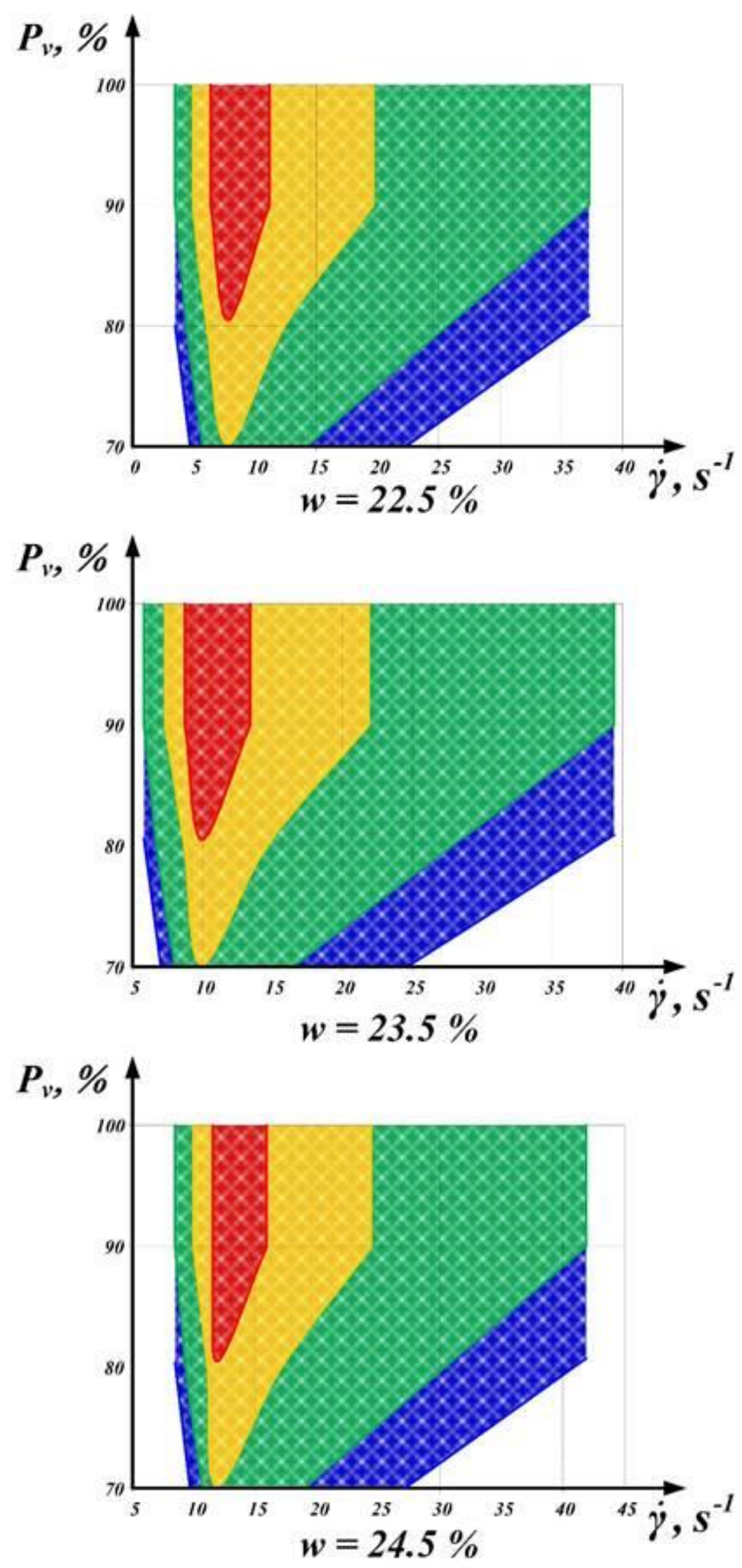

Fig. 7. The cross-sections of the space of technological parameters of the ceramic paste extrusion process in $P_{v}-\dot{\gamma}$ plane. 
Based on the analysis of the surfaces obtained (Fig. 6, 7), we proposed an automatic control system structure for an auger vacuum extruder (ACS for AVE) to manufacture the ceramic stones [11]. The structure consists of three separate channels and includes a multidimensional object of control, by which we understand the combination of hydrodynamic and electromechanical processes in the preparation of clay raw materials and the shaping of bars and subsequent drying and firing processes. The state of the object is determined by $\mathbf{Y}$ vector. We use the following as converting elements: in shear rate control channel $\dot{\gamma}$ - frequency converter to power the extruder drive; in the control channel for the $P_{v}$ value - frequency converter for the vacuum pump motor; in the moisture control channel $w-$ pulse-width modulators for powering the coils of the solenoid valves supplying water and steam to the extruder mixer.

The synthesized space of technological parameters of the ceramic paste extrusion $\langle\Pi\rangle_{\text {is }}$ incorporated into the vector of master signals for the ACS for AVE and can be adjusted depending on the data obtained during production. The arrangement and implementation of such an automation system allows to establish the competitive brick production, to ensure an increase in productivity and to reduce the specific energy consumption along with stabilizing the brick strength matching the given class requirements.

\section{Conclusion}

The paper describes the technique allowing the visualization of the space of technological parameters of the ceramic paste extrusion process. At first, this stage was considered using the approaches of system analysis, identification of objects of control and automatic control theory, which allowed to isolate the vectors of control and disturbing influences, the vector of controlled variables, elements of which were taken as coordinates of the multidimensional parameter space of the extrusion process.

The authors analyzed the results of few and scattered studies to assess the impact of the main parameters, most characterizing the efficiency of an auger vacuum extruder (shear rate and moisture levels of the ceramic paste in the pressure head and the level of vacuum pressure in the vacuum chamber), on the quality of the finished product, and first of all on its strength. This made it possible to represent the sought space in the form of a threedimensional graphic design, in which the iso-areas of brick classes are visually displayed in coordinates corresponding to the elements of the vector of controlled variables. It should also be noted that a structural representation of the multidimensional relationship between the shear rate, the moisture of the ceramic paste, the vacuum pressure and the strength class was obtained, which is essential in preparing and conducting computational experiments.

Studying sections of the found space of technological parameters has greatly facilitated the creation of the structure of the automation system for an auger vacuum extruder and the algorithms for its rational work.

The conducted survey reflects the results of one of the stages of research work on the synthesis of the structure and the formation of the software for the digital automatic control system for the production of ceramic bricks.

\section{References}

1. Khimicheskaya tekhnologiya keramiki [Chemical technology of ceramics] / edited by I.Ya. Guzman. Moscow, Stroymaterialy, 2003. 496 p. [in Russian].

2. Zolotarskiy A.Z., Sheynman E.Sh. Proizvodstvo keramicheskogo kirpicha [Ceramic brick production]. Moscow, Vysshaya shkola, 1989. 264 p. [in Russian]. 
3. Tolkachev V.Ya. Tekhnologiya kachestvennoy ekstruzii izdeliy iz glin [Technology of high-quality extrusion of clay products]. Krasnoyarsk, Kompyuternyye tekhnologii, 2009. 220 p. [in Russian].

4. Barabanshchikov Yu.G. Vliyaniye skorosti formovaniya na prochnost stroitelnykh izdeliy [The effect of shaping speed on the strength of building products] // Nauchnotekhnicheskiye vedomosti SPbGPU, № 6-1, 2006, pp. 170-175. [in Russian].

5. Avgustinik A.I. Keramika [Ceramics]. Leningrad, Stroyizdat (Leningr. otd-niye), 1975. 592 p. [in Russian].

6. Tretiakov I.M., Golubovich S.R. Shnekovyye vakuum-pressy i vakuumnyye ustanovki [Auger vacuum extruders and vacuum systems]. Moscow, Gosudarstvennoye izdatelstvo literatury po stroitelnym materialam, 1953. 92 p. [in Russian].

7. GOST 530-2012 Kirpich i kamen keramicheskiye. Obshchiye tekhnicheskiye usloviya [Ceramic brick and stone. General technical conditions]. Moscow, Standartinform, 2012. 39 p. [in Russian].

8. Handle F. Extrusion in Ceramics. Berlin, Springer, 2007. 468 p.

9. Barabanshchikov Yu.G. Formirovaniye struktury i prochnosti stroitelnykh materialov pri trenii vodosoderzhashchikh syryevykh smesey [Formation of structure and strength of the building materials in friction raw water containing mixtures]. Sankt-Peterburgskiy gosudarstvennyy politekhnicheskiy universitet, Saint-Petersburg, 2006. 292 p. [in Russian].

10. Silenok S.G. Mekhanicheskoe oborudovanie predpriyatiy stroitelnyikh materialov, izdeliy i konstruktsiy [Mechanical equipment of enterprises of building materials, products and structures] / S.G. Silenok, A.A. Borschevskiy, M.N. Gorbovets. Moscow, Mashinostroenie, 1990. 416 p. [in Russian].

11. Galitskov S.Ya., Nazarov M.A., Galitskov K.S. Structure of Intelligent Control System of Auger Vacuum Extruder for Ceramic Bricks' Manufacturing // International Journal of Applied Engineering Research, 2015, Volume 10, Number 20, pp. 40846-40852.

12. Nazarov M.A., Kantseva A.M. Matematicheskoye opisaniye protsessa vakuumirovaniya keramicheskoy massy pri proizvodstve kirpicha kak obyekta upravleniya [Mathematical description of vacuuming ceramic paste process in bricks production as an object of control] // Traditsii i innovatsii v stroitelstve i arkhitekture. Stroitelnyye tekhnologii: sbornik statey / SGASU, Samara, 2016, pp. 455-460. [in Russian].

13. Galitskov S.Ya., Ivanov K.A., Nazarov M.A., Sabanov P.A., Pimenov E.K. Matematicheskoye opisaniye protsessa podgotovki keramicheskoy massy $\mathrm{v}$ dvukhvalnom glinosmesitele kak obyekta upravleniya [Mathematical description of ceramic paste preparing process in a two-shaft clay mixer as an object of control] // Nauchnoye obozreniye, 2014, № 6, pp. 84-89. [in Russian].

14. Leisenberg W. Moisture measurement on ceramic raw materials // Zigelindustrie International, 2000, № 8, pp. 25-32.

15. Nichiporenko S.P. Osnovnyye voprosy teorii protsessov obrabotki i formovaniya keramicheskikh mass [The main issues of the theory of processing and shaping ceramic pastes]. Kiyev, Izdatelstvo akademii nauk Ukrainskoy SSR, 1960. 112 p. [in Russian]. 